\title{
JOB SAFETY ANALYSIS OF A TOP DRIVE MACHINE IN MOBILE OFFSHORE DRILLING UNITS
}

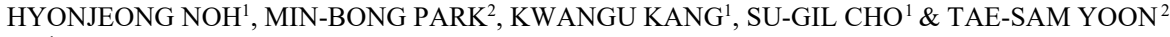 \\ ${ }^{1}$ Offshore Equipment Research Center, Korea Research Institute of Ships \& Ocean Engineering, \\ Republic of Korea \\ ${ }^{2}$ Korea Offshore Company, Republic of Korea
}

\begin{abstract}
Mobile Offshore Drilling Units (MODUs) are in charge of drilling operations at offshore environment. A derrick system, which handles drill pipes, risers, casing, blowout preventer, etc., and delivers such equipment to subsea is one of most important part in MODUs. Among the derrick system equipment, a top drive machine is regarded as the most dangerous because of the unexpected swinging movement of a tope drive machine by large wave. As a top drive machine is heavy and large, this swinging movement can lead workers to injuries or fatality. In this regards, this study aims to identify risky tasks related to a top drive machine during its maintenance and to suggest risk reducing measures by conducting a Job Safety Analysis. We categorized the maintenance tasks depending on the six top drive machine equipment and analysed their hazards and consequences. Among these tasks, maintenance of the weight compensating system was judged to be the most dangerous job, and measures to reduce the risk were proposed. The results of this study could be used to lower the risk of future drilling work.

Keywords: Job Safety Analysis (JSA), offshore drilling, Top Drive Machine (TDM), risk analysis, maintenance.
\end{abstract}

\section{INTRODUCTION}

The drilling units allow us to confirm the availability of oil and gas that are expected to be presented in the sediments through seismic exploration, and to product those resources. In order to perform such drilling, a general drilling unit consists of drilling and hoisting system, rotating system, mud flow system, and pipe handing system. Unlike onshore, offshore drilling rigs can be moved depending on the location of the oil and gas field. These drilling rigs are called Mobile Offshore Drilling Units (MODUs).

Derrick is installed at the upper part of MODUs. Derrick provides space for drilling related works such as connecting, disassembling, descending and rising of the drilling pipe, and is built to maintain the load of pipe. Above all, derrick has a Top Drive Machine (TDM) that enables drilling. As drilling is the core function of MODUs, the TDM is one of primary system. In the case of offshore plants such as MODUs, maintenance work must be carried out continuously to maintain their function without failing or rusting, even if they are not producing or operating. However, the maintenance work of large and heavy equipment like a TDM exposes workers to many risks. Also, maintenance work can be dangerous if workers do not follow proper procedures or make mistakes. In this manner, this study analysed the risk of maintenance work related to the top drive machine in MODUs and suggested the riskreducing measures in order to contribute to lowering the risk of workers.

\section{METHODOLOGY}

In this study, we conducted a Job Safety Analysis (JSA) to analyse the risk of work related to maintenance of top drive machine in MODUs. A JSA is an effective method to analyse potential risks that may be happened during job procedures and practices [1].

The procedure of the JSA is shown in Fig. 1. First, select a job to carry out a JSA. List all tasks related to the job and identify all hazards for each task. Categorize frequencies and 


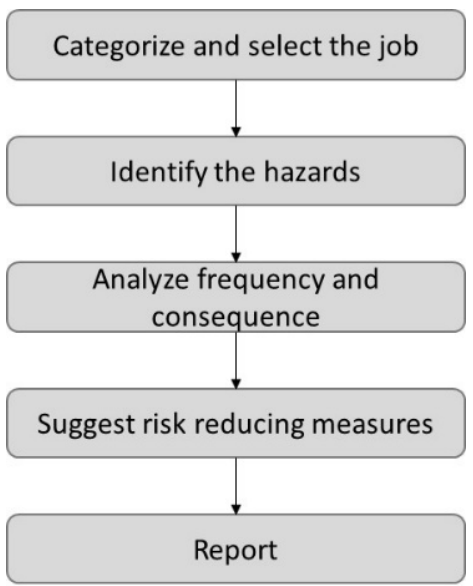

Figure 1: Procedure of the JSA.

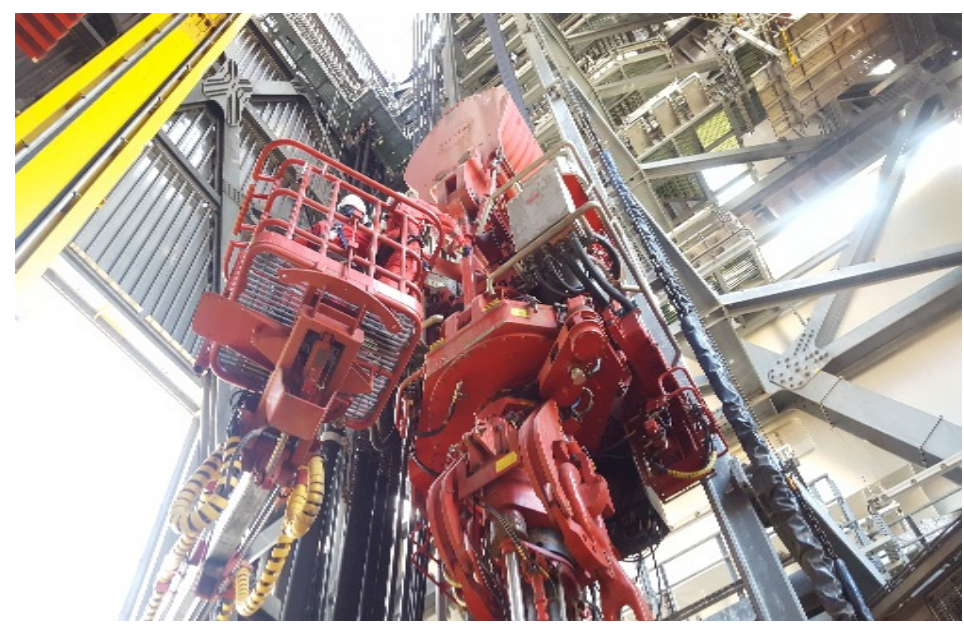

Figure 2: A TDM hung on top and the workers carrying out maintenance work.

consequences of the resulting hazards. Then, propose a risk-reducing measure to reduce the hazard. These JSAs usually identify hazards and potential accidents at each stage of the task and develop measures to eliminate, minimize, and prevent hazards and accidents [2].

According to the methodology described above, we divided the main equipment which constitute the TDM and list related tasks of the maintenance work for the equipment. Then, we analysed the risks arising from the maintenance work of each equipment. The main results of this analysis are described in the next section.

\section{RESULTS}

In the Derrick systems, the major role of a TDM is turning the drill string. The motor mounted on the TDM rotates the drill pipe. The TDM is hanging on a traveling block and the traveling 
block moves the TDM up and down along the guide rail installed on the side of the derrick system. The guide rail, also called dolly, enables the unshaking up and down movement and hold the TDM upright while supporting torque due to pipe rotation. Since the TDM is large and heavy, and hanging on the top, it can be unexpectedly swung by waves during maintenance. Therefore, the attention of workers on the drill floor is highly required during maintenance. Fig. 2 clearly shows hung TDM and maintaining workers.

The TDM consists of swivel, gearbox, pipe handler, torque wrench, IBOP, weight compensating system, dolly, and etc., see Fig. 3. Table 1 shows the roles of each equipment.

The risk matrix defined in this study is shown in Table 2. Table 2 shows a tabular illustration of the risk grade reflecting frequencies and consequences of accidents which may be occurred during maintenance works.

We divided the levels of frequencies and consequences into five, respectively. Larger numbers in frequency and consequence level represents greater risk. Then, the risks are

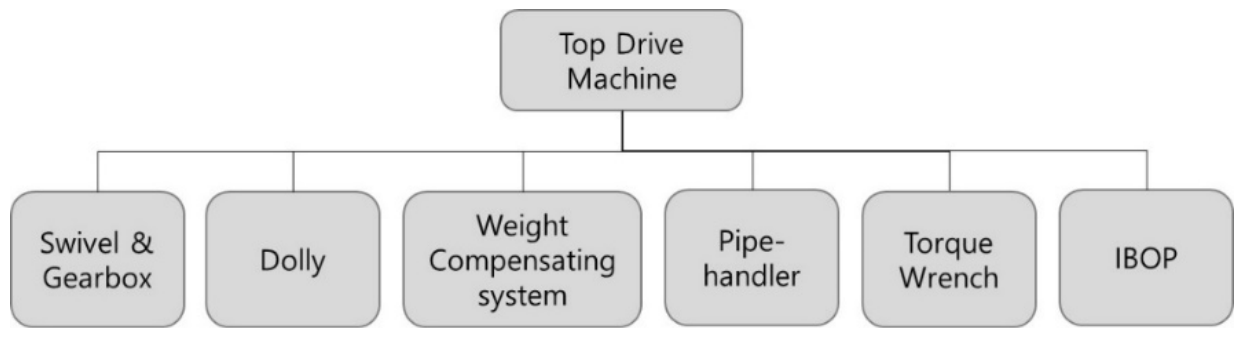

Figure 3: Equipment of the TDM.

Table 1: Functions of TDM equipment.

\begin{tabular}{|l|l|}
\hline Equipment & Functions \\
\hline $\begin{array}{l}\text { Gear box and } \\
\text { swivel }\end{array}$ & $\begin{array}{l}\text { - Transfer power to the main shaft through gear box } \\
\text { - Connect the lower part to the rotating part }\end{array}$ \\
\hline $\begin{array}{l}\text { Pipe handler } \\
\text { and elevator }\end{array}$ & $\begin{array}{l}\text { - Handle the elevator to load / unload pipes } \\
\text { - Grip pipes }\end{array}$ \\
\hline $\begin{array}{l}\text { Retractable } \\
\text { dolly }\end{array}$ & $\begin{array}{l}\text { - Fix the whole system of TDM. } \\
\text { TDM a guide to operate up and down movement of } \\
\text { TDithout shaking }\end{array}$ \\
\hline $\begin{array}{l}\text { Torque } \\
\text { wrench }\end{array}$ & $\begin{array}{l}\text { - } \text { Pithstand the torque due to pipe rotation. } \\
\text { pipe with exact torque value }\end{array}$ \\
\hline $\begin{array}{l}\text { Weight } \\
\text { compensating } \\
\text { system }\end{array}$ & $\begin{array}{l}\text { - Compensate the height of TDM to prevent damage to } \\
\text { the drill pipe threads when tightening the drill pipe. }\end{array}$ \\
\hline
\end{tabular}


Table 2: Risk matrix of the maintenance works for TDM.

\begin{tabular}{|c|c|c|c|c|c|c|}
\hline \multicolumn{2}{|c|}{ Consequence } & 1 & 2 & 3 & 4 & 5 \\
\hline & equency & $\begin{array}{l}\text { Minor } \\
\text { injuries or } \\
\text { discomfort. } \\
\text { No medical } \\
\text { treatment }\end{array}$ & $\begin{array}{l}\text { Injuries or } \\
\text { illness } \\
\text { requiring } \\
\text { medical } \\
\text { treatment. }\end{array}$ & $\begin{array}{l}\text { Injuries or } \\
\text { illness } \\
\text { requiring } \\
\text { hospital } \\
\text { admission. }\end{array}$ & $\begin{array}{l}\text { Injury or } \\
\text { illness } \\
\text { resulting } \\
\text { permanent } \\
\text { impairment. }\end{array}$ & Fatality \\
\hline 1 & Rare & 1 & 1 & 1 & 1 & 3 \\
\hline 2 & Unlikely & 1 & 1 & 2 & 3 & 4 \\
\hline 3 & Possible & 1 & 2 & 3 & 4 & 5 \\
\hline 4 & Likely & 3 & 3 & 4 & 5 & 5 \\
\hline 5 & Very likely & 3 & 4 & 5 & 5 & 5 \\
\hline
\end{tabular}

divided into five grades according to the frequency and consequence levels as shown in Table 2. Grade 1 (green zone) and 2 (light green zone) mean that risk is acceptable level. Grade 3 (yellow zone) and 4 (orange zone) indicate that further analysis and risk-reducing measures are required to mitigate the risk to tolerable level within available budget. Grade 5 (red zone) means that risk reduction measure must be carried out with the highest priority. Usually the frequency of grade 5 is lowered rather than consequence because the consequence of accident is difficult to be lowered.

Table 3 shows the fifteen major TDM maintenance tasks by component and their JSA results. The analysis showed that the five tasks were the highest risk grade (red colour parts in Table 2). Two maintenance tasks of a weight compensating system corresponding to grade 5 were found to be the most dangerous. The accident probability of the tasks is "Likely" which can lead workers to fatality. The task of maintaining the pipe hander, the "Adjustment of Clearance between Trust Nut and Link Hanger", was the second most dangerous. The task was analysed at high risk because the probability of an accident is "Possible", but it could lead to death if an accident occurred. Lastly, "Washpipe mounting" and "Replacing Saver Sub / IBOP / intermediate Sub" among the tasks of maintaining the gear box and swivel were found to be dangerous. The task were analysed as the third most dangerous task because the likelihood of an accident was "Likely", but the accident does not lead workers to fatality.

The results of the JSA indicates that maintenance of TDM is highly risky overall. This is because the TDM is large and heavy and hangs on the traveling block. Given the fact that the working environment of MODUs is offshore, it should always be kept in mind that TDM can be unexpectedly moved by waves.

The worker must be well trained and aware of the fact that maintenance of the TDM is very dangerous. The results of this study could be used to lower the risk of future drilling work. By publishing the results in the workspace, workers can refer to them before they start to work and/or at any time. The use of these JSA results is critical to reducing the risk of the operation. 


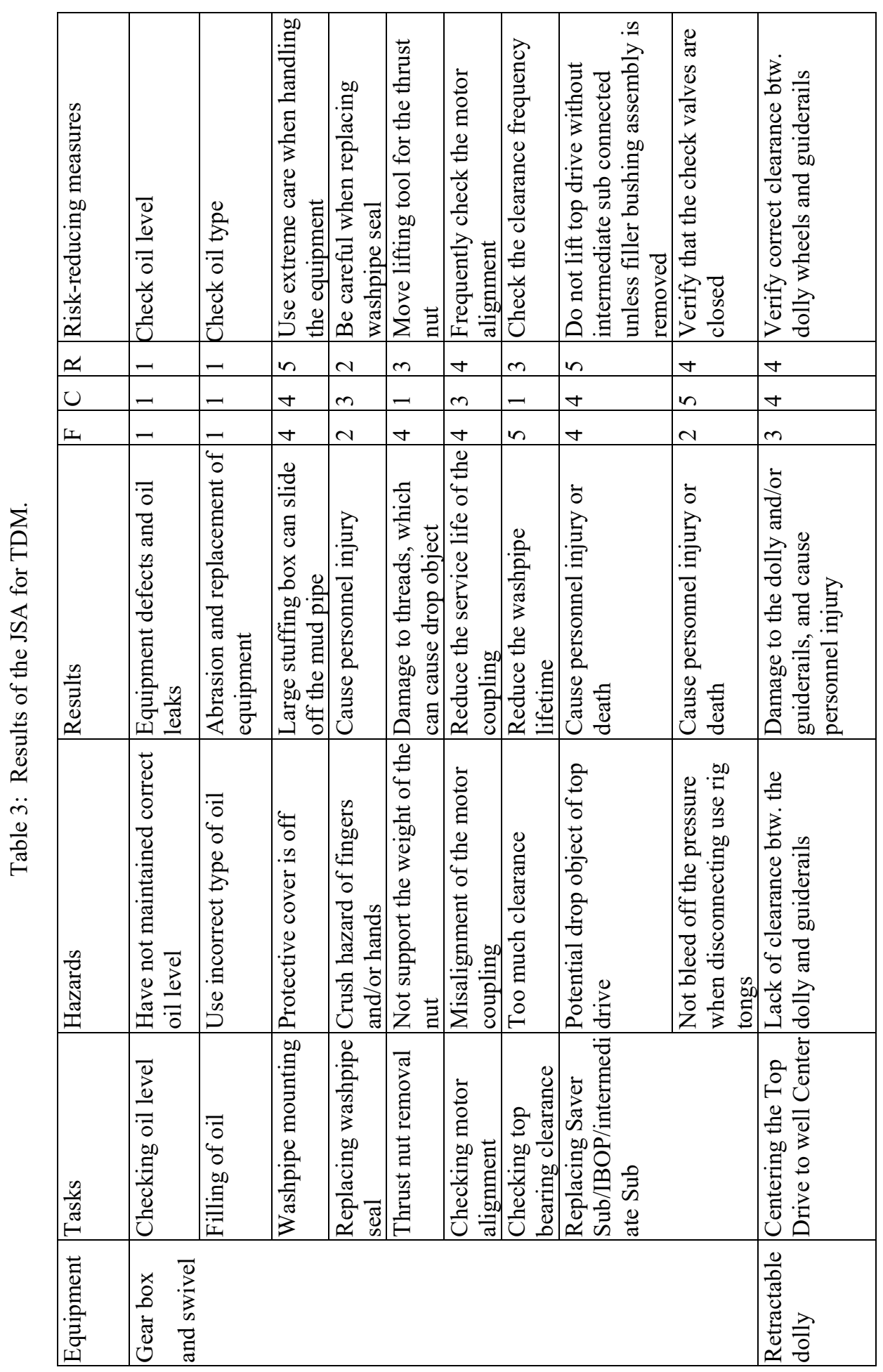




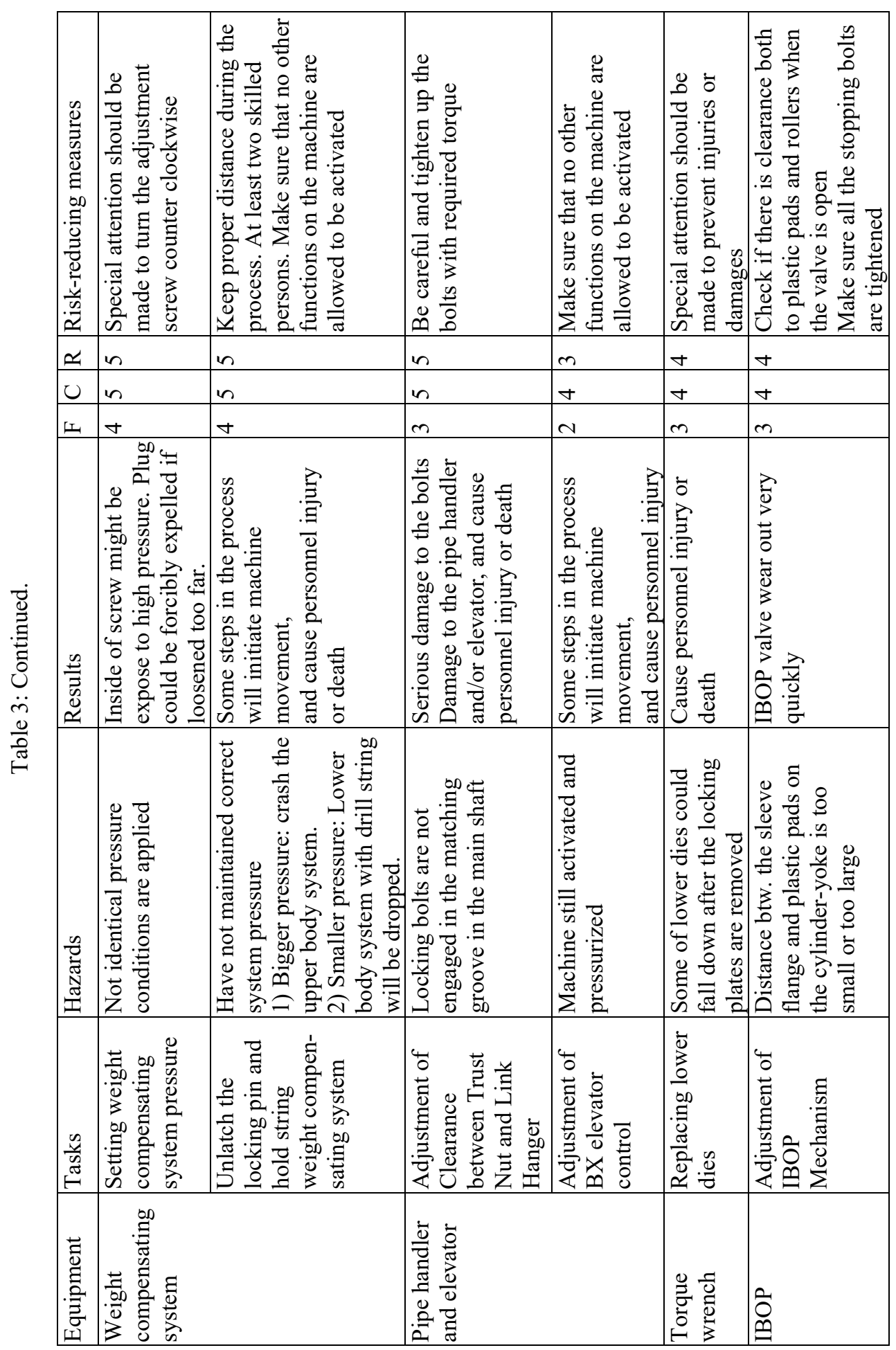




\section{CONCLUSION}

In this study, we analysed the risk of maintenance tasks for the TDM in MODUs by conduction the JSA. We divided the maintenance tasks by equipment which constitute the TDM, i.e. gear box and swivel, pipehandler and elevator, torque wrench, IBOP, weight compensating system, and dolly. Fifteen tasks were classified for six equipment. We also defined the risk matrix to analyse the hazards and consequences of the tasks. The results showed that the tasks relating to the weight compensating system were the most dangerous. The probability of the task was "Likely", and it could lead workers to fatality. And the JSA results also indicated that maintenance of TDM are highly risky overall. Special attention with correct work procedure should be carried out to reduce the risk. The JSA results need to be informed to workers before starting work so that they can refer and be careful during maintenance.

\section{ACKNOWLEDGEMENT}

This research is supported by a grant from Endowment Project of "Technology development of material handling and risk management for operation and maintenance service of offshore plant" funded by the Korea Research Institute of Ships \& Ocean Engineering (PES9331).

\section{REFERENCES}

[1] U.S. Department of Labor, Occupational Safety and Health Administration, Job Hazard Analysis, OSHA 3071, 2002.

[2] Rausand, M., Risk Assessment: Theory, Methods, and Applications, John Wiley \& Sons, Inc.: Hoboken, NJ, 2011. 